\title{
Gold Mesh Antenna for Canada's Communications Satellite
}

\author{
HIGH REFLECTIVITY AND CONSTANT ORIENTATION
}

The first satellite to be launched for a national communications network, Canada's Anik I is now in synchronous orbit 22,300 miles above the equator. The first of three to be built by Hughes Aircraft and two Canadian sub-contractors, Spar Aerospace Products and Northern Electric, it has the capacity to handle more than 5,000 telephone circuits or twelve channels of colour television. For the first time in its history, Canada has the opportunity to develop nationwide communications wherever ground stations can be established to receive and transmit signals from Anik. Initially it will be used by the Canadian Broadcasting Corporation, by the TransCanadian Telephone System, and by Bell Canada.

Anik is owned and operated by Telestat Canada, a corporation set up by the government in 1969 with the specific mandate of providing all forms of telecommunications between Canadians, from the American border to the Arctic and from the Atlantic to the Pacific Ocean. A second Anik (the name is the Eskimo word for brother) is to be launched by N.A.S.A. in April, and a third will be held in reserve on the ground.

One of the design problems associated with Anik was the positioning of its antenna in relation to the ground and the avoidance of the tipping effect caused by the pressure of solar radiation. This has been overcome by employing a woven mesh of gold plated wire stretched over the antenna, a 60-inch parabolic structure. Nickel-chromium alloy wire 0.0005 inch in diameter was woven into interlocking loops using seven strands in a tricot weave. This type
The first Canadian communications satellite being assembled at Hughes Aircraft Company in EI Segundo, California. The 60-inch parabolic antenna is covered with fine gold mesh to reduce the effect of solar radiation when the satellite is in synchronous orbit 22,300 miles over the equator. Known as Anik I-two more are to be constructed-the satellite has the capacity to provide more than 5,000 telephone circuits or 12 colour television channels to link Canada's enormous area extending over $3,800,000$ square miles

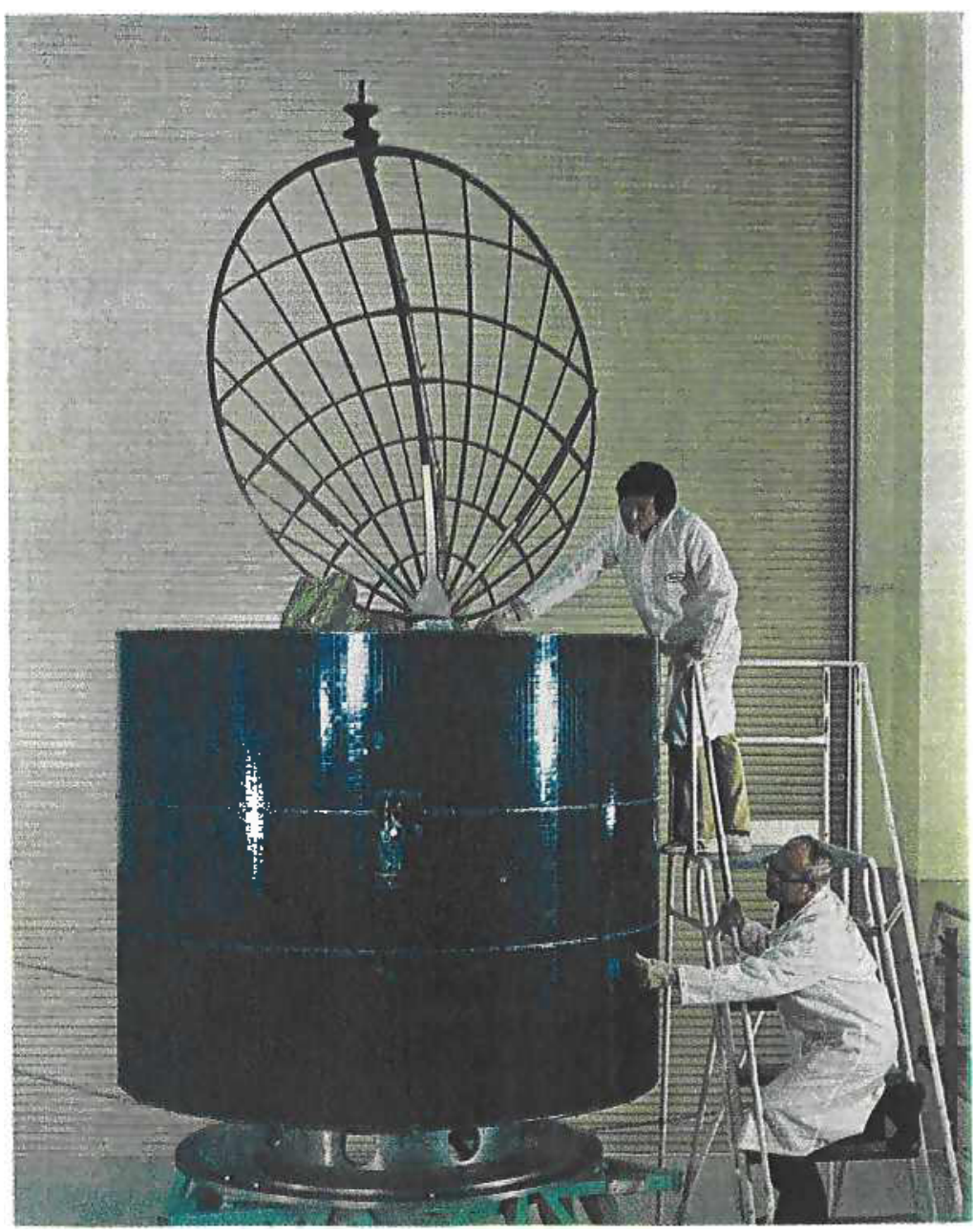


A detail of the loosely woven mesh of gold plated nickelchromium wires which forms the antenna of the Anik satellite. The open weave combined with the high reflectivity of gold minimise the effects of solar radiation pressure and ensure correct positioning of the antenna

of mesh is capable of considerable stretching, unlike conventional weaving, and was chosen to enable the mesh to be formed to the correct shape. The mesh was then gold plated and attached to its framework.

As the gold plated mesh consists in large proportion of open holes, the pressure effect of radiation from the sun is minimised and the antenna maintains its precise position for optimum coverage in relation to the ground stations.

The high reflectivity of gold, as well as its high electrical conductivity at radio frequencies, ensure maximum efficiency of the antenna, while its high reflectivity in the infra-red range helps to maintain a constant antenna temperature.

While this application of gold is the first for a commercial communications satellite, the same type of construction has been used in other space exploration equipment. The small antenna set up by the astronauts on the moon to transmit television

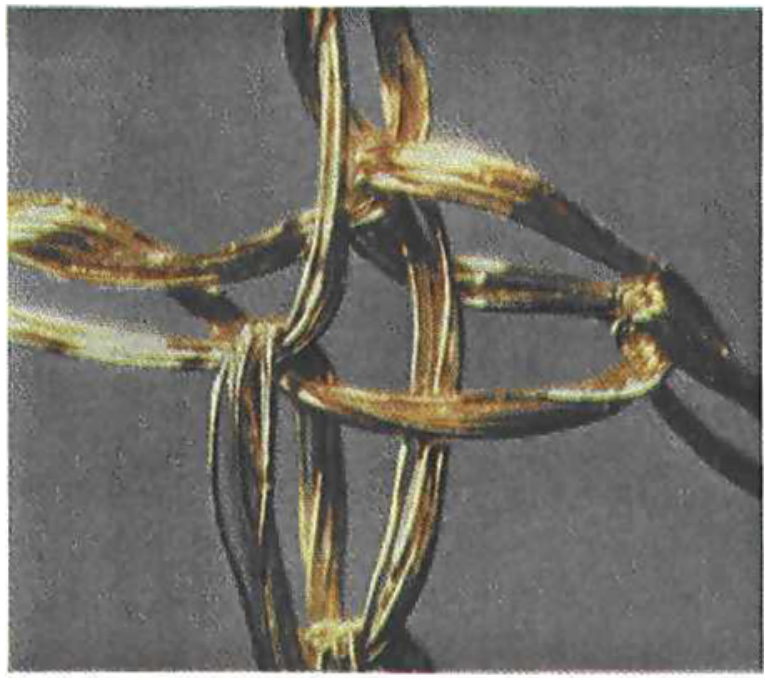

pictures of their journeys on foot and in the lunar rover also employed gold plated mesh to ensure the excellent quality of transmission and reception achieved over a quarter of a million miles.

Three additional communications satellites, identical with the Anik series, are to be built by Hughes Aircraft for Western Union Telegraph Company as the first United States domestic satellites, the first being scheduled for delivery in early 1974.

\section{Gold Plated Plastic Light Fittings}

An architectural feature combining decorative effect, good reflectivity for light and yet economy has been devised for the elevators in one of the world's largest buildings, the 80-storey headquarters of

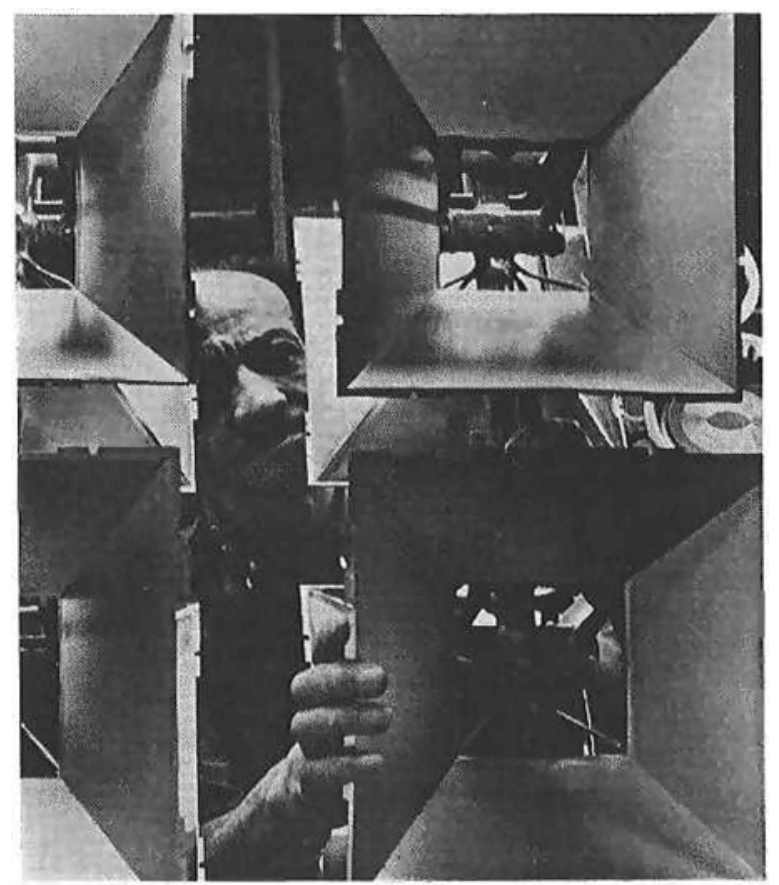

Standard Oil of Indiana now being erected in Chicago.

The design for the elevators specified that the ceiling lights should be diffused through square coffers or enclosures holding translucent plastic lenses over the fluorescent tubes, 48 coffers making up each elevator car ceiling. Polypropylene mouldings were chosen for their construction, being lighter in weight and lower in cost than the die-castings originally proposed by the architect.

The plastic mouldings are first etched, then given a nickel electrodeposit of about 0.0005 inch thickness, and finally gold plated, using an alloy gold solution developed by Technic, Inc., of Providence, Rhode Island. This bath, known as Côte d'Or, is capable of long production runs and gives a hard long-wearing deposit. In all over 4,000 coffers were gold plated.

The gold plated finish is less expensive than brass plating followed by lacquering on account of the less number of operations involved, while an additional advantage is the high reflectivity of the gold surface and, of course, its permanence.

Installing some of the gold plated polypropylene light enclosures in the elevators of the 80-storey Standard Oil building now being erected in Chicago 